\title{
Formation of a metastable ferromagnetic $\tau$ phase during containerless melt processing and rapid quenching in Mn-Al-C alloys
}

\author{
Y. J. Kim and J. H. Perepezko \\ Department of Materials Science and Engineering, University of Wisconsin-Madison, Madison, \\ Wisconsin 53706
}

(Received 3 July 1991; accepted for publication 10 October 1991)

\begin{abstract}
Solidification of selected $\mathrm{Mn}-\mathrm{Al}-\mathrm{C}$ alloys during containerless levitation and rapid quenching has yielded the first report for a ferromagnetic metastable $\tau\left(L 1_{0}\right)$ phase formed directly from the melt. Complete solidification to $\tau$ phase was interrupted by the competitive evolution of an equilibrium $\epsilon$ phase during recalescence. The amount of undercooling required to produce the metastable ferromagnetic $\tau$ phase in a $\mathrm{Mn}_{0.55} \mathrm{Al}_{0.433} \mathrm{C}_{0.017}$ alloy during solidification was estimated as approximately $470 \mathrm{~K}$ based on differential thermal analysis results. When the alloy carbon content was increased to 3.4 at. \% (i.e., $\mathrm{Mn}_{0.55} \mathrm{Al}_{0.416} \mathrm{Co}_{0.034}$ alloy), a transition in structure development occurred so that the samples exhibited $\gamma_{2}$ phase formation as well as $\tau$ and $\epsilon$ phases. Both microstructural observations and $\mathrm{x}$-ray diffraction examination were used to guide the interpretation and the analysis of solidification pathways. The attainment of the high liquid undercooling required to nucleate the metastable $\tau$ phase from the melt may be facilitated by containerless processing.
\end{abstract}

\section{INTRODUCTION}

In the $\mathrm{Mn}-\mathrm{Al}$ system a ferromagnetic metastable $\tau$ phase forms with the CuAuI $\left(L 1_{0}\right)$ structure and is highly anisotropic with the easy axis of magnetization in the [001] direction. ${ }^{1}$ In practice, the $\tau$ phase has been produced only by solid-state heat treatments in the composition range of 49 at. $\% \mathrm{Mn}$ to 60 at. \% $\mathrm{Mn}$ as indicated by the shaded area in Fig. $1 .^{2}$ There are several solid-state transformation pathways to develop the $\tau$ phase such as quenching the high-temperature $\epsilon$ phase (hcp) followed by an annealing of the retained $\epsilon$ phase below $600^{\circ} \mathrm{C}$ or cooling the $\epsilon$ phase at rates of the order of $15 \mathrm{~K} / \mathrm{s}^{3}$ Particularly in the latter method, at slow cooling rates (i.e., $<15 \mathrm{~K} / \mathrm{s}$ ) the $\epsilon$ phase decomposes into the equilibrium $\gamma_{2}$ and $\beta$ phase, while fast rates result in retention of the $\epsilon$ phase. $^{3}$

Despite both the technological and scientific importance of the ferromagnetic metastable $\tau$ phase in the $\mathrm{Mn}$-Al system, the magnetic properties of alloys $\left[H_{c}, B_{n}(B H)_{\max }\right]$ with the $\tau$ phase formed by conventional solid-state heat treatments have not yet been optimized due to the defects developed in the solid-state transformation (i.e., $\epsilon \rightarrow \tau$ ). ${ }^{4}$ These defects include antiphase boundaries, twins, and stacking faults. ${ }^{2}$ The presence of a domain structure in MnAlC alloy magnets produced by solid-state transformation $(\epsilon \rightarrow \tau)$ is the most significant factor limiting the magnetic properties of the finished product. ${ }^{5}$

In early work, Ohtani et al. ${ }^{6}$ reported that alloying additions such as carbon ( $<16$ at. $\%$ ) to $\mathrm{Mn}_{x}-\mathrm{Al}_{1-x}$ alloys $(0.49 \leqslant x \leqslant 0.60)$ increase the saturation magnetization and stabilize the $\tau$ phase against decomposition as well as promote machinability and improved mechanical properties. It was also reported that to improve the permanent magnetic properties the carbon content must exceed the solubility limit in the $\tau$ phase, i.e., about 1.4 at. $\% \mathrm{C}$ at 53 at. $\% \mathrm{Mn}$ and 2.1 at. $\% \mathrm{C}$ at 55 at. $\% \mathrm{Mn}$.

Both the defect structures and decomposition reactions reduce the magnetic performance of Mn-Al-C alloys, how- ever, even with these defects, the magnetic properties are very attractive for permanent magnet applications. For example, an anisotropic MnAlC magnet has a $(B H)_{\max }=58.9 \mathrm{~kJ} \mathrm{~m}^{-3}$ which is intermediate between the values obtained in ferrite magnets $\left(24-32 \mathrm{~kJ} \mathrm{~m}^{-3}\right)$ and rare-earth-cobalt magnets $\left(160-280 \mathrm{~kJ} \mathrm{~m}^{-3}\right)$ while it is in the same range as the Alnico magnets $\left(40-65 \mathrm{~kJ} \mathrm{~m}^{-3}\right)$. In addition, material costs for $\mathrm{Mn}-\mathrm{Al}-\mathrm{C}$ are far lower and $\mathrm{Mn}$ sources are widely distributed. ${ }^{7}$ Therefore, the optimization of the magnetic properties of Mn-Al-C alloys has been an area of active research.

Since the nucleation site which initiates solidification at high cooling rate may favor the formation of an alternative product such as a metastable phase structure associated with a high level of undercooling, rapid solidification processing provides an unique technique for modifying the microstructural development during solidification. For instance, Inoue et al. ${ }^{8}$ have studicd the solidification behavior of alloys in the $\mathrm{Mn}$-Al-C system by the use of the in-rotating-water spinning method. A metastable fec phase was produced in the composition ranges from 9 to 22 at. $\%$ $\mathrm{Al}$ and 3.0 to 6.5 at. \% $\mathrm{C}$ due to the rapid cooling rate and associated melt undercooling at the onset of solidification instead of the equilibrium $\left(\alpha-M n+\beta-M n+M_{23} C_{6}\right)$ phase mixture. Other metastable phase products were observed in alloys with compositions outside of the domain for development of the metastable fec solid solution. For example, with increasing $\mathrm{Al}$ levels a metastable extension of a hep phase develops from the Mn-Al system and at increasing $\mathrm{C}$ levels an ordered $\mathrm{fcc}$ phase was observed. Thus, rapid liquid quenching of undercooled Mn-Al-C alloys does offer the potential for significant structural modification. However, it should also be noted that Inoue et al. ${ }^{8}$ did not report any evidence for the development of the metastable tetragonal $\tau$ phase as a direct solidification product.

In other recent studies, several authors have studied the magnetic properties of Mn-Al-C alloys produced by 
wt. \% Mn

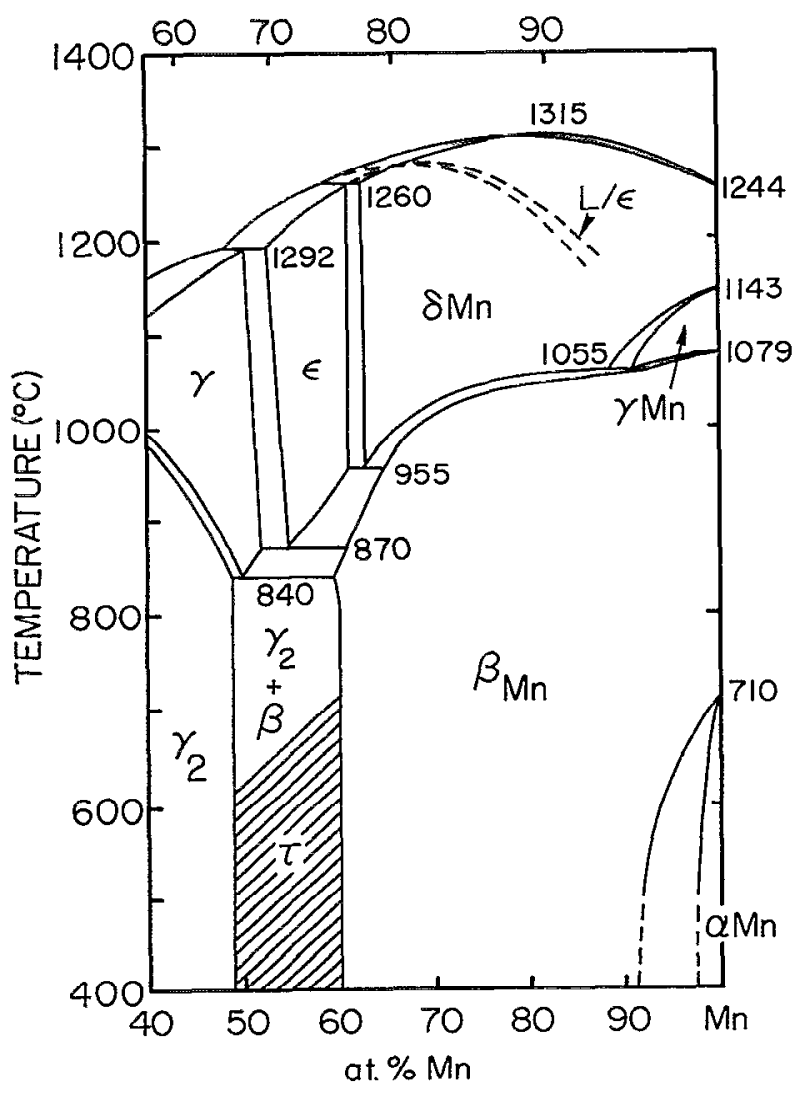

FIG. 1. Portion of the Mn-Al phase diagram (Ref. 19). The metastable extensions (dashed lines) of the $\epsilon$ phase liquidus and solidus boundaries and the reported domain of existence of the metastable $\tau$ phase (shaded region) are indicated.

rapid quenching techniques. For example, Berkowitz et al. ${ }^{9}$ have studied the magnetic properties of $\mathrm{Mn}-\mathrm{Al}-\mathrm{C}$ magnets prepared by spark erosion, melt spinning, and gas-water atomization. In their study, the major phase produced by solidification was again the hexagonal (hcp) $\epsilon$ phase from which a ferromagnetic metastable $\tau$ phase was formed by subsequent conventional solid-state heat treatment. Similarly, Sakka et al. ${ }^{10}$ have reported that the structure of as-quenched ribbons of a $\mathrm{Mn}$-Al-C alloy using a single roller method was identified as a retained high-temperature equilibrium $\epsilon$ phase. It should be emphasized that in all the previous applications of rapid solidification processing (RSP) techniques to Mn-Al-C alloys only the high-temperature $\epsilon$ phase has been reported to form from the melt. Conventional heat treatment methods have then been applied to the RSP product to produce $\tau$ phase.

There are several rapid solidification techniques, but they are not all equivalent in terms of the actual solidification conditions during processing. One obvious difference is melt cooling rate which has been estimated to vary from $10^{5}$ to $10^{8}{ }^{\circ} \mathrm{C} / \mathrm{s} .{ }^{11}$ This difference can be important in terms of the kinetic competition that prevails and the thermally induced undercooling levels which are required to allow for alternate phase formation. In this regard, containerless levitation melting with its advantage of melt cleanliness prior to splat quenching may play a role in allowing for the nucleation and/or growth of a thermodynamically metastable phase from the liquid and was applied in the present investigation to study microstructural evolution in undercooled Mn-Al-C alloys. In fact, information obtained from the present analysis has been coupled with the results from earlier solid-state transformation studies to provide a more complete understanding of the overall structural evolution during solidification with containerless melt processing and the conditions promoting metastable $\tau$ phase formation.

\section{EXPERIMENTAL PROCEDURE}

The purities of the starting materials used in preparing the ingots for both alloy compositions $\mathrm{Mn}_{0.55} \mathrm{Al}_{0.433} \mathrm{C}_{0.017}$ and $\mathrm{Mn}_{0.55} \mathrm{Al}_{0.416} \mathrm{Co}_{0.034}$ were $99.999 \% \mathrm{Al}$, 99.9\% $\mathrm{Mn}$ (electrolytic), and ultrahigh purity graphite (Grade UF4S). The compositional homogeneity was verified by energy-dispersive spectrometry. Prior to making the alloys, the surface of the pure $\mathrm{Mn}$ was cleaned with a nitric acid solution to remove surface contaminants and oxide. The cleaned pure $\mathrm{Mn}$ was then arc-melted at least three times to reduce the hydrogen content. Alloy ingots of approximately $10 \mathrm{~g}$ in total weight were prepared from the cleaned pure metals with a high frequency induction furnace. Graphite powders $(<54 \mu \mathrm{m}$ in diameter) were placed at the bottom of an alumina susceptor and the pieces of $\mathrm{Mn}$ and $\mathrm{Al}$ elements were overlaid on the graphite powders to ensure the complete wetting between graphite powders and the other alloy elements during melting process.

The ingots were heated at $1400^{\circ} \mathrm{C}$ under an $\mathrm{Ar}$ gas environment and held for about $4 \mathrm{~h}$ to ensure that the graphite powder had gone into solution. Following induction furnace melting, the ingots were encapsulated in tubes of fused silica under vacuum and held in a furnace at $1100^{\circ} \mathrm{C}$ for $20 \mathrm{~h}$, followed by ice-water quenching to attain homogenization. From the homogenized ingots, 100-300mg pieces were chosen for levitation melting in a radiofrequency field $(2100 \mathrm{kHz})$ and splat quenching of the molten droplet between two copper anvils. The splat quenching apparatus (Bühler) permitted argon backfilling from a $1-\mathrm{mPa}$ vacuum, and molten metal durations were on the order of $2 \mathrm{~s}$ before splat quenching.

The homogenized ingots and splats $(<30 \mu \mathrm{m}$ in thickness) were analyzed with $\mathrm{x}$-ray diffraction (XRD) using a Siemens $\mathrm{x}$-ray diffractometer operating with $\mathrm{Cu} K \alpha$ radiation in the reflection (Bragg-Brentano) mode to identify the phases present. Along with XRD, physical examination using a permanent magnet was also carried out to judge whether or not the processed sample splats exhibited ferromagnetic properties. Furthermore, since $\tau$ phase is the only ferromagnetic phase in the $\mathrm{Mn}-\mathrm{Al}-\mathrm{C}$ alloy system, the experimental confirmation of the $\tau$ phase was made by the magnetic powder pattern metallographic technique using a magnetic colloidal suspension of fine $\mathrm{Fe}_{3} \mathrm{O}_{4}$ particles $\left(\approx 0.03 \mu \mathrm{m}\right.$ in diameter). ${ }^{12}$ After examining the as-solidified samples, differential thermal analysis curves were obtained for the splat samples with a Perkin Elmer DTA System 1700 using $\mathrm{Al}_{2} \mathrm{O}_{3}$ as the reference material. The 


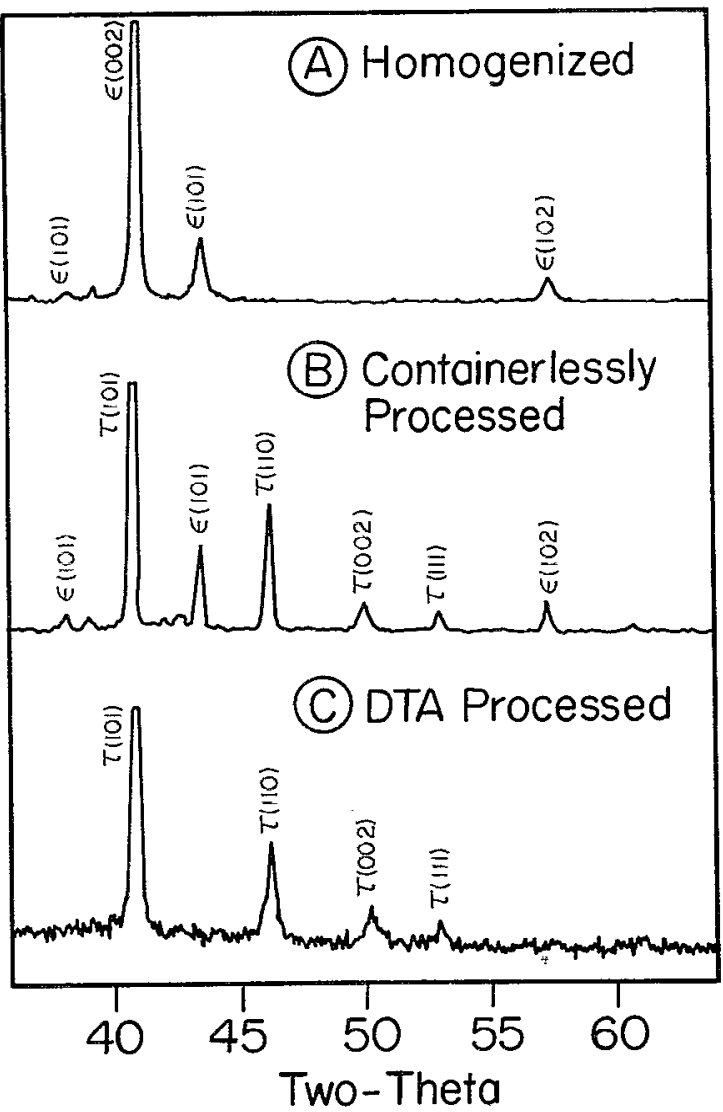

FIG. 2. XRD patterns of the $\mathrm{Mn}_{0.55} \mathrm{Al}_{0.433} \mathrm{C}_{0,017}$ alloy. Trace $\mathrm{A}$ is that of a homogenized ingot, while trace $B$ corresponds to the pattern of a containerlessly melted and splat quenched sample. Trace $C$ is that of a DTA processed sample as-cooled from above $T_{L}$ (cooling rate $=20 \mathrm{~K} / \mathrm{min}$ ).

heating rate was kept at $10 \mathrm{~K} / \mathrm{min}$ with a cooling rate at 20 $\mathrm{K} / \mathrm{min}$. Metallographic preparation of interior splat sections consisted of mechanical polishing and etching with a $4 \%$ HF water solution. The splat microstructure was then evaluated using optical and scanning electron microscopy (SEM) with secondary electron imaging.

\section{RESULTS AND DISCUSSION}

$\mathrm{X}$-ray analysis of both alloy ingots after homogenization at $1100^{\circ} \mathrm{C}$ for $20 \mathrm{~h}$ followed by water quenching indicated the primary phase was the $\epsilon$ phase as shown in Figs. 2 (trace A) and 3 (trace A). This is consistent with previous reports that high solid-state quench rates do not favor the development of $\tau$ phase. In other words, the hightemperature $\epsilon$ phase is easily retained at above the critical cooling rate $(15 \mathrm{~K} / \mathrm{s})$. After containerless processing and solidification of the $\mathrm{Mn}_{0.55} \mathrm{Al}_{0.433} \mathrm{C}_{0.017}$ alloy, the structure of the sample reveals the initiation of $\tau$ phase formation as indicated through the XRD pattern in Fig. 2 (trace B) and the cross-sectional SEM micrograph in Fig. 4(a). This implies that the containerless melting and rapid cooling rate may allow a heterogeneous nucleation site active at lower cooling rates to be kinetically bypassed, with the splat attaining a deep level of undercooling prior to the onset of solidification. ${ }^{13}$ Again, it is worth pointing out that there is

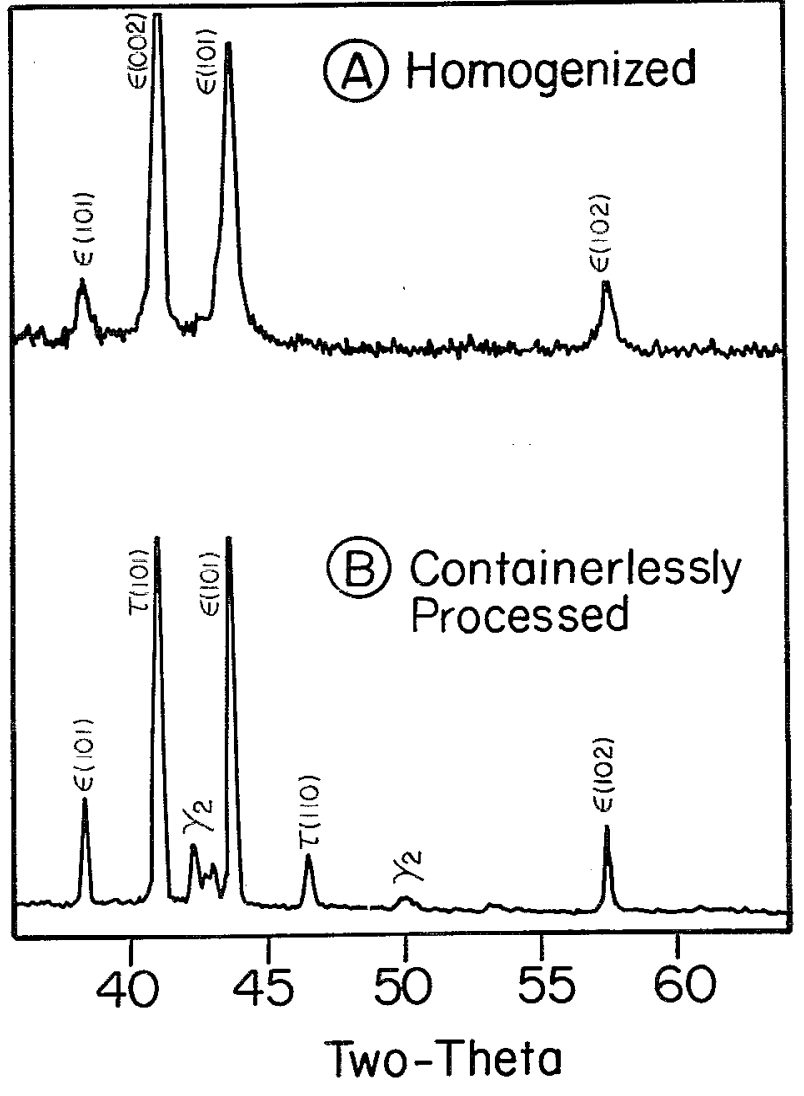

FIG. 3. XRD patterns of the $\mathrm{Mn}_{0.55} \mathrm{Al}_{0.416} \mathrm{C}_{0.034}$ alloy. Trace $\mathrm{A}$ is that of a homogenized ingot sample, while trace $B$ corresponds to the pattern of a containerless melt processed and splat quenched sample.

a critical solid-state cooling rate range of the order of 15 $\mathrm{K} / \mathrm{s}$ as indicated in XRD results of the homogenized ingots. In fact, this critical cooling rate in the solid state is well exceeded by the splat quenching process and thus $\tau$ phase in the splat sample is not formed during cooling by the solid-state transformation $(\epsilon \rightarrow \tau)$. In addition, physical examination using a permanent magnet indicated that the splat quenched sample exhibited a strong ferromagnetic property. Therefore, as shown with the XRD pattern in Fig. 2 (trace B) and physical examination, the development of a ferromagnetic metastable $\tau$ phase directly from the melt, i.e., without solid-state heat treatments, is possible with a control of liquid undercooling levels through containerless processing and rapid liquid quenching.

In the splat quenched $\mathrm{Mn}_{0.55} \mathrm{Al}_{0.433} \mathrm{C}_{0.017}$ alloy sample, the microstructure, as shown through the SEM micrograph in Fig. 4(a), consists predominantly of a metastable $\tau$ phase which grew initially with a plane front parallel to the splat copper anvils. Subsequent breakdown of the planar interface occurred towards the center of the splat, resulting in an equiaxed microstructure of the $\epsilon$ phase. This microstructural evolution can be understood by the initial nucleation and growth of a metastable $\tau$ phase from the significantly undercooled melt, and, with recalescence, solidification of remaining liquid in the center region of splat by the formation of the $\epsilon$ phase. In other words, the growth 


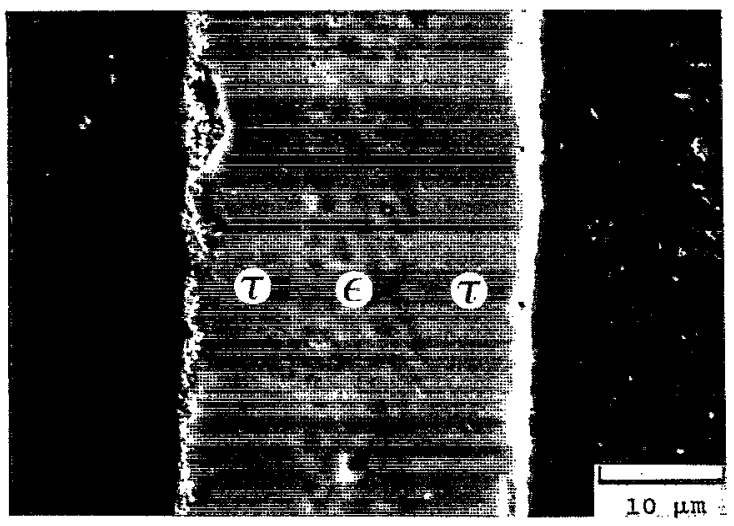

(a)

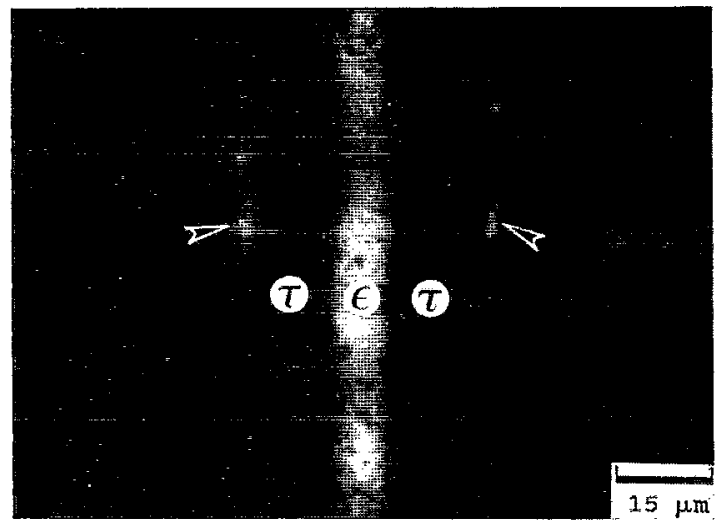

(b)

FIG. 4. (a) SEM micrograph of the cross section of the splat quenched $\mathrm{Mn}_{0.55} \mathrm{Al}_{0.433} \mathrm{Co}_{0.017}$ alloy. (b) Optical micrograph of magnetic powder patterns on the cross section of the splat quenched $\mathrm{Mn}_{0.55} \mathrm{Al}_{0.433} \mathrm{C}_{0.017}$ alloy. Note the confinement of the colloid magnetic particles over the ferromagnetic $\tau$ phase (dark) and absence on the nonferromagnetic $\epsilon$ phase (bright).

rate of the $\tau$ phase into the undercooled liquid decreases as the temperature increases due to the heat of fusion released by crystallization of the $\tau$ phase during recalescence. Thus, the decreased growth rate allows time for the $\epsilon$ phase to nucleate and overrun the $\tau$ phase. To provide a confirmation for analysis of the microstructural evolution observed in this splat sample, the powder pattern metallographic technique was used in agreement with the XRD result. Since the $\epsilon$ phase is nonferromagnetic while $\tau$ is ferromagnetic, the powder pattern technique using a magnetic colloidal suspension of the $\mathrm{Fe}_{3} \mathrm{O}_{4}$ particles deposited on the mechanically polished and unetched surface of the splat sample did not give any pattern of powder deposits at the center region of splat indicating the presence of the $\epsilon$ phase as shown in Fig. 4(b).

In the containerlessly processed and quenched high carbon $\mathrm{Mn}_{0.55} \mathrm{Al}_{0.416} \mathrm{C}_{0.034}$ alloy the solidification pattern showed several similarities to that observed in the low carbon alloy $\left(\mathrm{Mn}_{0.55} \mathrm{Al}_{0.433} \mathrm{C}_{0.017}\right)$. The solidification struc-

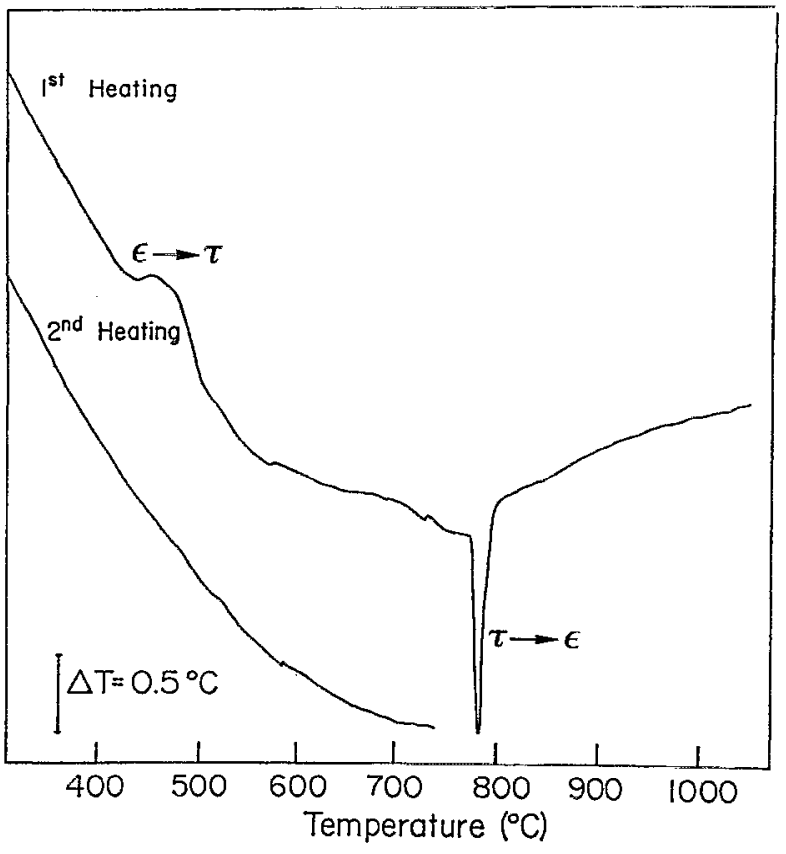

FIG. 5. DTA thermograms of the splat quenched $\mathrm{Mn}_{0.55} \mathrm{Al}_{0.433} \mathrm{C}_{0.017}$ alloy.

tures, as identified through the XRD pattern in Fig. 3 (trace B), consisted mainly of the metastable $\tau$ phase and $\epsilon$ phase, but there was also some evidence for a small amount of the $\gamma_{2}$ phase. Metallographic examination of the splat foil cross section revealed a similar microstructure as in the low carbon alloy with the $\tau$ phase located mainly near the foil surface and $\epsilon$ near the foil center. The similarity in microstructure between the low and high carbon samples and the sluggish solid-state kinetics of the $\gamma_{2}$ phase $^{14}$ suggests that a small amount of the $\gamma_{2}$ structure may develop during final freezing in the post-recalescence stage. Further study is needed to confirm this suggestion.

During conventional heat treatments ${ }^{3}$ to produce the $\tau$ phase, the complete transformation of $\epsilon$ phase to $\tau$ phase has been reported to proceed in the following sequence ${ }^{15,16}$ during heating:

$$
\text { disordered } \epsilon(\mathrm{hcp}) \stackrel{\text { ordering }}{\rightarrow} \epsilon^{\prime}(B 19) \stackrel{\text { martensitic }}{\rightarrow} \tau\left(L 1_{0}\right) \text {. }
$$

The ordering of the $\epsilon$ phase which yields the $\epsilon^{\prime}(B 19)$ phase demands a diffusion process, while the martensitic transformation of the $\epsilon^{\prime}$ phase into the $\tau$ phase is a diffusionless (i.e., athermal) transformation. DTA examination of the $\mathrm{Mn}_{0.55} \mathrm{Al}_{0.433} \mathrm{C}_{0.017}$ splats revealed exothermic and endothermic peaks in thermograms as shown in Fig. 5. Upon the first heating of the fresh splat sample, which consisted mainly of a $\tau$ phase with some retained $\epsilon$ phase, an exothermic peak was observed in the temperature region between 400 to $500^{\circ} \mathrm{C}$ due to the transformation of the retained $\epsilon$ phase to the ferromagnetic metastable $\tau$ phase through ordering and martensitic transformation. The endothermic peak observed at $780^{\circ} \mathrm{C}$ on heating shown in Fig. 5 was due to the transformation of the $\tau$ phase back to the $\epsilon$ phase. It is worth mentioning that the 


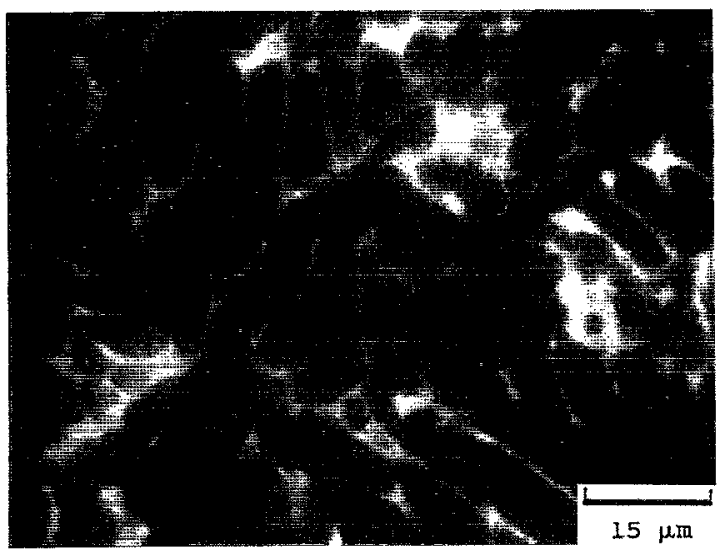

FIG. 6. Optical micrograph of magnetic powder pattern on the DTA processed $\mathrm{Mn}_{0.55} \mathrm{Al}_{0.433} \mathrm{C}_{0.017}$ alloy highlighting the $\tau$ phase regions (dark) that formed in the solid state from the $\epsilon$ phase. The remnant hexagonal dendritic morphology due to solidification of $\epsilon$ is evident.

exolhermic peak in the temperature range 500 to $550^{\circ} \mathrm{C}$ is significantly weaker than that reported by Rao et al. ${ }^{17}$ due to the fact that the splats consisted primarily of a ferromagnetic metastable $\tau$ phase. In fact, Rao et al. ${ }^{17}$ have produced a metastable $\tau$ phase again by solid-state transformation, i.e., the $\tau$ phase was formed from the retained $\epsilon$ phase upon heating. Since complete solid-state transformation $(\epsilon \rightarrow \tau)$ occurred during cooling (cooling rate $=20$ $\mathrm{K} / \mathrm{min}$ ) from the splat sample cycled past the liquidus temperature, the second heating DTA curve displayed no evidence of transformation of the $\epsilon$ phase to the $\tau$ phase. Consequently, since the transformation of the $\epsilon$ phase to the $\tau$ phase was completed in the DTA treatment, the $x$-ray diffraction pattern of this DTA treated sample indicated only the presence of the $\tau$ phase as shown in Fig. 2 (trace $\mathrm{C}$ ). This was confirmed by the observation of the magnetic domain structure as shown in Fig. 6. It is important to point out that the metastability of the ferromagnetic $\tau$ phase is retained readily up to around $780{ }^{\circ} \mathrm{C}$ upon heating because of the sluggish decomposition of $\tau$ to equilibrium $\gamma_{2}$ and $\beta$ phase as indicated in both the DTA trace (Fig. 5) and the study of Dreizler et al. ${ }^{14}$

As the focus of the present investigation was to study the microstructural development of a ferromagnetic $\tau$ phase directly from the melt in Mn-Al-C alloys, it was valuable to obtain the approximate level of undercooling required for the $\tau$ phase formation. DTA thermograms exhibited evidence of phase transformation of a metastable $\tau$ phase to hcp $\epsilon$ phase with occurrence of an endothermic reaction upon heating at $780^{\circ} \mathrm{C}(1053 \mathrm{~K})$ as shown in Fig. 5. Using $1053 \mathrm{~K}$ as a bound on nucleation temperature of the $\tau$ phase, $T_{N}$, the approximate level of the undercooling, $\Delta T(\mathrm{~K})$, which is required for $\tau$ phase formation of samples processed in the splat quenching process can be estimated as $0.31 T_{L}(\approx 470 \mathrm{~K})$, where $T_{L}$ is the equilibrium liquidus temperature of the $\mathrm{Mn}_{0.55} \mathrm{Al}_{0.433} \mathrm{Co}_{0.017}$ alloy $(\approx 1523 \mathrm{~K})$. It is apparent that containerless levitation melting which minimizes potential contamination and possible heterogeneous nucleation sites, as well as the high cooling rate in the splat quenching process compared to other previous RSP techniques, has significant advantages in promoting large undercooling which plays an essential role in the microstructural development for $\tau$ phase formation as a solidification product without conventional solidstate transformation. Indeed, in other work ${ }^{18}$ it has been possible to obtain essentially single phase samples of the $\tau$ structure by optimizing the containerless melt processing conditions.

\section{CONCLUSIONS}

(1) A metastable ferromagnetic $\tau$ phase has been produced, for the first time, directly from the melt in both $\mathrm{Mn}_{0.55} \mathrm{Al}_{0.433} \mathrm{C}_{0.017}$ and $\mathrm{Mn}_{0.55} \mathrm{Al}_{0.416} \mathrm{C}_{0.034}$ alloys by a containerless processing method involving levitation melting followed by quenching.

(2) The minimum amount of undercooling level required for the ferromagnetic metastable $\tau$ phase formation in a $\mathrm{Mn}_{0.55} \mathrm{Al}_{0.433} \mathrm{C}_{0.017}$ alloy was estimated as approximately $470 \mathrm{~K}$ (i.e., $0.31 T_{L}$ ) using the results from differential thermal analysis measurements and an analysis of the phase equilibria. The attainment of this undercooling level in the present work may be facilitated by the application of containerless melt processing.

\section{ACKNOWLEDGMENT}

Y. J. K. and J. H. P. gratefully acknowledge the support of NASA (Grant No. NAG-8-771).

${ }^{1}$ A. J. J. Koch, P. Hokkeling, M. G. V. D. Steeg, and K. J. De Vos, J. Appl. Phys. 31, 75S (1960).

${ }^{2}$ J. V. Landuyt, G. V. Tendeloo, J. J. v.d. Broek, H. Donkersloot, and H. Zijlstra, IEEE Trans. Magn. MAG-14, 679 (1978).

${ }^{3}$ H. Kono, J. Phys. Soc. Jpn. 13, 1444 (1958).

${ }^{4}$ N. I. Vlasova, G. S. Kandaurova, Ya. S. Shur, and N. N. Bykhanova, Phys. Met. Metall. 51, 1 (1981).

${ }^{5} J$. J. Wyslocki and S. Szymura, J. Mater. Sci. 19, 1261 (1983).

${ }^{6}$ T. Ohtani, N. Kato, S. Kojima, Y. Sakamoto, I. Konno, M. Tsukamara, and T. Kubo, IEEE Trans. Magn. MAG-13, 1328 (1977).

${ }^{7}$ G. L. DeHuff, Minerals Yearbook 1975, USDI Bur. Mines, Washington, DC (1977), Vol. 1, p. 879.

${ }^{8}$ A. Inoue, H. Tomioka, and T. Masumoto, Met. Trans. A 14, 2319 (1983).

A. E. Berkowitz, J. D. Livingston, and J. L. Walter, J. Appl. Phys. 55, 2106 (1984).

${ }^{10}$ Y. Sakka, M. Naksmura, and K. Hoshimoto, J. Mater. Sci. 24, 4331 (1989).

${ }^{11}$ H. Jones, Rep. Prog. Phys. 36, 1425 (1973).

${ }^{12}$ R. J. Gray, Magnetics Etching with Ferrofluid, in Metallographic Specimen Preparation (Plenum, New York, 1974), pp. 155-177.

${ }^{13} \mathrm{~J}$. H. Perepezko, in Proceedings of the 2 nd International Conference on Rapid Solidification Processing: Principles and Technologies II, edited by R. Mehrabian, B. H. Kear, and M. Cohen (Claitor', Baton Rouge, LA, 1980), p. 56.

${ }^{14}$ W. H. Dreizler and A. Menth, IEEE Trans. Magn. MAG-16, 534 (1980).

${ }^{15}$ S. Kojima, T. Ohtani, N. Kato, K. Kajima, Y. Sakamoto, I. Konno, M. Tsukahara, and T. Kubo, AIP Conf. Proc. No. 24 (AIP, New York, 1974), p. 768.

${ }^{16}$ J. J. Van Den Broek, H. Donkershout, G. Van Tendeloo, and J. Van Landuyt, Acta Metall. 27, 1497 (1979).

${ }^{17}$ V. Rao, S. Pramanik, C. R. Tewari, S. R. Singh, and O. H. Mohanty, J. Mater. Sci. Lett. 24, 4088 (1989).

${ }^{18}$ Y. J. Kim and J. H. Perepezko (to be published).

${ }^{19}$ A. J. McAlister and J. L. Murray, Bull. Alloy Phase Diag. 8, 438 (1987). 